\title{
Copy Number Amplification of the PIK3CA Gene Is Associated with Poor Prognosis in Non-lymph node metastatic Head and Neck Squamous Cell Carcinoma
}

\author{
Toshihito Suda ${ }^{1}$, Takanori Hama ${ }^{1,2^{*}}$, Shu Kondo ${ }^{3}$, Yuki Yuza ${ }^{4}$, Mamoru Yoshikawa', \\ Mitsuyoshi Urashima ${ }^{2,4}$, Takakuni Kato ${ }^{1}$ and Hiroshi Moriyama ${ }^{1}$
}

\begin{abstract}
Background: Deregulation of the EGFR signaling pathway is one of the most frequently observed genetic abnormalities that drives cancer development. Although mutations in the downstream components of the EGFR signaling pathway, including KRAS, BRAF and PIK3CA, have been reported in numerous cancers, extensive mutation and copy number analysis of these genes in clinical samples has not been performed for head and neck squamous cell carcinoma (HNSCC).

Methods: We examined the mutations and copy number alterations of KRAS, BRAF and PIK3CA in 115 clinical specimens of HNSCC obtained from surgically treated patients.

We used DNA sequencing to detect mutations and the copy number changes were evaluated by qPCR and array comparative genomic hybridization (CGH) analysis.

Results: We examined the mutations and copy number alterations of KRAS, BRAF and PIK3CA in 115 clinical specimens of HNSCC obtained from surgically treated patients. We identified 3 mutations (2.6\%) in K-RAS and 3 mutations (2.6\%) in PIK3CA. Copy number amplification was found in 37 cases (32.2\%) for PIK3CA, 10 cases (8.7\%) for K-RAS and 2 cases (1.7\%) for BRAF. Kaplan-Meier survival analysis revealed that copy-number amplification of PIK3CA was markedly associated with cancer relapse in patients without lymph node metastasis. (Log-rank test, $p=0.026$ )

Conclusions: Copy number amplification of the PIK3CA gene is associated with poor prognosis in HNSCC patients without lymph node metastasis. The PIK3CA copy number status will serve as a marker of poor prognosis in patients with HNSCC.
\end{abstract}

Keywords: PIK3CA, KRAS, BRAF, Copy number analysis, Prognostic Factor

\section{Background}

Progress in genomics has led to the identification of oncogenes, and genetic mutations associated with carcinogenesis have been reported for many carcinomas. Furthermore, an increase in the gene copy number due to focal amplification or chromosomal polysomy is

\footnotetext{
*Correspondence: takanori@jikei.ac.jp

'Department of Oto-Rhino-Laryngology, Jikei University School of Medicine,

3-25-8 Nishi-shimbashi, Minato-ku, Tokyo 105-8461, Japan

${ }^{2}$ Division of Molecular Epidemiology, Jikei University School of Medicine,

Minato-ku, Tokyo, Japan

Full list of author information is available at the end of the article
}

another major mechanism of oncogene activation [1]. In addition to progress in the understanding of signaling pathways, there have been pharmaceutical advances with regard to the development of drugs that target proteins in membrane receptors and the downstream signals associated with carcinogenesis. Various trials have been performed to assess individualized drugs for the treatment of cancer that target the patients' individual genetic makeup, and numerous agents targeting various cancer-related proteins have recently been developed.

Recent studies have shown that the over expression of epidermal growth factor receptor (EGFR) is associated

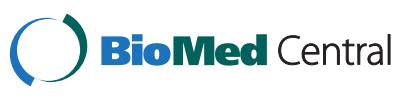


with a poor prognosis in patients with head and neck squamous cell carcinoma (HNSCC) [2]. In a previous study, we analyzed the mutations and phosphorylation status of EGFR in patients with HNSCC and showed that the hyperphosphorylation of EGFR was a prognostic factor for poor survival [3]. Accordingly, the EGFR signaling pathway has attracted attention in the field of HNSCC as a promising target for molecularly targeted treatment. Indeed, cetuximab, a chimeric monoclonal antibody directed against human EGFR, has been reported to be effective in the treatment of advanced HNSCC [4].

Upon binding with a ligand, EGFR activates multiple intracellular signaling pathways, including the RAS/ RAF/mitogen-activated protein kinase (MAPK) pathway and the phosphoinositide 3-kinase (PI3K)/AKT/mammalian target of rapamycin (mTOR) pathway, which transmit extracellular signals to the nucleus to control cell growth and proliferation. In many types of malignancies, such as lung cancer and colorectal cancer, mutations in the genes encoding EGFR or downstream components of the signaling pathways are highly prevalent $[5,6]$. Interestingly, these mutations are often associated with the effectiveness of molecularly targeted drugs. For instance, mutations in KRAS are effective predictors of colorectal cancer patients' responses to cetuximab [7], and mutations in PIK3CA are correlated with resistance to cetuximab treatment in colon cancer cell lines [8]. Therefore, in the era of personalized cancer therapy, it will be important to know whether these mutations are present in tumors to plan effective therapeutic strategies for patients. So we determined a type of the mutation to investigate in reference to some theses about HNSCC in KRAS, BRAF, and PIK3CA $[9,10]$.

In addition to gene mutations, copy number alterations of EGFR, KRAS, PIK3CA and other signaling mediators are also critical factors that drive cancer development and determine prognoses and the sensitivity to anticancer drugs. In NSCLC, EGFR gene copy amplification, as determined by FISH, was shown to likely be associated with poor prognosis and with improved survival upon treatment with EGFR tyrosine kinase inhibitors [11]. As for HNSCC, several reports have shown that EGFR copy number alterations are associated with a poor prognosis [12]; it is also reported that PIK3CA copy number amplification is associated with lymph node metastasis [13].

Little is known about the frequency of mutations and copy number alterations of genes other than EGFR that encode components of the RAS and PI3K pathways in HNSCC. Herein, we present a sequence and copy number analysis of the RAS, RAF and PI3K genes in a collection of 115 clinical samples.

\section{Methods}

\section{Patients}

This prospective cohort study was approved by the Ethics Committee for Biomedical Research of the Jikei Institutional Review Board, Jikei University School of Medicine, Tokyo, Japan. All of the patients provided written informed consent. Between September 2006 and August 2009, 115 tumors were obtained from 115 HNSCC patients who underwent surgery at the Department of Head and Neck Surgery, Jikei University Hospital. And they were consecutively submitted by surgical management. Clinical information was obtained from the clinical and surgical charts. Based on the postoperative staging, the tumor-node-metastasis (TNM) classification and stage were determined according to the 6th UICC TNM classification and stage groupings [14].

\section{Tumor samples}

In each case, the tumor samples from the primary site and surrounding normal tissue, but not the metastatic sites, were stored at $-80^{\circ} \mathrm{C}$ after excision. The cancer tissue was divided into two specimens: one for pathological confirmation in which the sample was composed of $>70 \%$ cancer cells and the other for DNA and protein extraction.

\section{Mutation analysis}

We used DNA sequencing to detect mutations in the clinical HNSCC specimens. Polymerase chain reaction (PCR) amplification of genomic DNA was performed, and the following genes were analyzed for mutations: KRAS (exons 1 and 2); BRAF (exon 15); and PIK3CA (exons 9 and 20). These regions included those with the most common mutations previously observed in human cancer. Table 1 shows the primers and annealing temperatures used in the PCR analysis. The sequencing of the PCR products was performed using the ABI PRISM Large Dye Terminator Cycle Sequencing Ready Reaction

Table 1 Primer sequences and annealing temperatures for direct sequencing

\begin{tabular}{|c|c|c|c|}
\hline Gene & Exon & Primer sequence & $\mathrm{Tm}$, \\
\hline \multirow[t]{4}{*}{ PIK3CA } & 9 & F,5'-TTGCTITTTCTGTAAATCATCTGTG-3' & 51 \\
\hline & & R, $5^{\prime}$-CCACAAATATCAATTTACAACCATTG-3' & \\
\hline & 20 & F,5'-GGTATTAACATCATTTGCTCCAA-3' & 52 \\
\hline & & R,5'-CCTATGCAATCGGTCTTTGC-3' & \\
\hline \multirow[t]{2}{*}{ KRAS } & 1 & F, & 52 \\
\hline & & R,5'-GTGAACATCATGGACCCTGACATACTCC-3' & \\
\hline$\overline{\text { BRAF }}$ & 15 & F,5'-TCATAATGCTTGCTCTGATAGGA-3' & 52 \\
\hline & & R,5-GGCCAAAATTTAATCAGTGGA-3' & \\
\hline
\end{tabular}

$\mathrm{F}$, forward primer $\mathrm{R}$, reverse primer $\mathrm{Tm}$, annealing temparature. We used DNA sequencing to detect mutations in the clinical HNSCC specimens. KRAS (exons 1 and 2), BRAF (exon 15) and PIK3CA (exons 9 and 20) were analyzed for mutations. 
kit and the ABI PRISM 3700 Genetic Analyzer (PE Applied Biosystems, Foster City, CA).

\section{Analysis of copy number by quantitative PCR}

The copy number changes in KRAS, BRAF and PIK3CA were evaluated by qPCR using the $\mathrm{qPCR}^{\mathrm{TM}}$ MasterMix for SYBR Green, as previously reported [15]. Table 2 shows the primer and annealing temperatures used in the qPCR; the qPCR reactions for each sample and each gene were performed in triplicate. Each copy number calculation was performed using the comparative $C_{t}$ method [16]. DNA from the normal tissue from each sample was used as the control [17]; each gene copy number in the normal tissue was set as 2 , and a copy number more than 4 was considered to be a gain, as in a previous study [18].

\section{Analysis of the copy number by array CGH}

For the samples with copy number amplification identified by qPCR, we performed an array comparative genomic hybridization (CGH) analysis using microarray slides that contained 180,000 probes (Agilent Technologies, Santa Clara, CA, USA) [19]. We defined log2 ratio $+0.5<$ as gain and $-0.5>$ as loss and all other amounts as normal.

\section{Statistical analysis}

The Student t-test, chi-squared test and Fisher test were used to evaluate differences in the patients' characteristics stratified by the copy number alternation. Diseasefree survival curve's end point is defined by recurrence (local relapse, new lymph node metastasis or distant metastasis) during follow. All patients conducted observation within two month after surgery and patients were periodically (every $0.5-2$ months) examined on an outpatient basis to make sure they had not relapsed. Examinations consisted of standard tests, including endoscopy and computed tomography of the chest and neck. It was defined recurrence when a carcinoma was detected again in a primary tumor and cervical lymph node or distant

Table 2 Primer sequences and annealing temperatures for copy number analysis by qPCR

\begin{tabular}{lll}
\hline Gene & Primer sequence & Tm, \\
\hline PIK3CA & F,5'- GCAAAGGTTGGTCGGTGAA -3' & 60 \\
\hline & R,5'- GTGATCTTTGATGTTACTCTGATGCA -3' & \\
\hline KRAS & F,5'- CACCCTAGACAAGCAGCCAATA -3' & 60 \\
\hline & R,5'- AAGCCCTGCCGCAAAAA -3' & \\
\hline BRAF & F,5'- CAAGTCACCACAAAAACCTATCGT - - ${ }^{\prime}$ & 60 \\
\hline & R,5- AACTGACTCACCACTGTCCTCTGTT - - ${ }^{\prime}$ & \\
\hline
\end{tabular}

The copy number changes in KRAS, BRAF and PIK3CA were evaluated by qPCR. DNA from the normal tissue from each sample was used as the control; each gene copy number in the normal tissue was set as 2 , and a copy number more than 4 was considered to be a gain. metastases were observed on computed tomography. Over-all survival and disease-free survival curves were generated using the Kaplan-Meier method and compared using log-rank tests. Cox proportional hazard models were fitted for multivariate analysis adjusting for age, gender, smoking status, mutation status of KRAS and PIK3CA, and amplification status. Adjusted hazard ratios (HR) and 95\% confidence intervals (CI) were computed. All of the statistical analyses were performed using STATA 9.1 (STATA Corp., College Station, TX). A $\mathrm{p}$ value $<0.05$ was considered statistically significant.

\section{Results}

\section{Patients' characteristics}

The patients ranged in age from 32 to 88 years, and there were more men than women in the cohort. Most of the patients had oropharyngeal or oral cavity cancer, and $47 \%$ had stage IV disease. The patient characteristics are listed in (Table 3).

\section{Mutation analysis of KRAS, BRAF and PIK3CA}

We conducted a sequencing analysis to examine the frequency of mutations in the KRAS, BRAF and PIK3CA genes, and we investigated the correlations between the presence of mutations and the clinical data. Specifically, we sequenced KRAS exon 1and exon2, BRAF exon 15 and PIK3CA exon 9 and exon 20 and identified mutations in 6 of the 115 patients (5.2\%). Three mutations were observed in exon 1 of KRAS, and all were the same substitution (G12A). No mutation was found in exon 2. The primary tumors included two oral cavity carcinomas and one oropharyngeal carcinoma; in terms of lifetime

Table 3 Patients' characteristics

\begin{tabular}{lc}
\hline Variable & Total $(\mathbf{n}=\mathbf{1 1 5})$ \\
\hline Age : mean \pm SD & $65.1 \pm 11.0$ \\
\hline Sex: Male/female & $93 / 22$ \\
\hline Primary site & $25(21.7 \%)$ \\
\hline Oropharyngeal & $25(21.7 \%)$ \\
\hline Hypopharyngeal & $23(20 \%)$ \\
\hline Laryngeal & $31(27 \%)$ \\
\hline Oral cavity & $11(9.6 \%)$ \\
\hline Nasal cavity & $45(39.1 \%) / 48(41.7 \%) / 22(19.1 \%)$ \\
\hline well/ moderate/poor & $16 / 45 / 27 / 27$ \\
\hline T stage: T1/T2/T3/T4 & $59 / 17 / 39 / 0$ \\
\hline N stage: N0/N1/N2/N3 & $(13.9 \% / 39.1 \% / 23.5 \% / 23.5 \%)$ \\
\hline Stage: I/II/II/IV & $(51.3 \% / 14.8 \% / 33.9 \% / 0 \%)$ \\
\cline { 2 - 2 } & $12 / 23 / 26 / 54$ \\
\hline
\end{tabular}

115 patients were obtained in this study. The patient characteristics are listed. 
smoking status (pack-years), one patient had a high score (more than 30 pack-years), and the others had low scores [20]. Three mutations in PIK3CA were found: two in exon 9 and one in exon 20, and all of the mutations were substitutions (E545K and H1047R). The primary tumors were two oral cavity carcinomas and one laryngeal carcinoma, and all three patients were nonsmokers. No BRAF mutations were detected (Table 4). Significant association was absent about the association between these mutations and clinical data (localization, sex, age,stage etc.).

\section{Copy number analysis of KRAS, BRAF and PIK3CA}

We identified copy number changes in PIK3CA, K-RAS and BRAF. PIK3CA copy number amplification was found in 37 cases (32.2\%), whereas only 10 cases (8.7\%) were found for K-RAS and 2 cases (1.7\%) for BRAF (Table 5). In PIK3CA amplified cases, one case had PIK3CA mutation, 2 cases had KRAS mutation and no case had both mutations. The patients' characteristics stratified by the PIK3CA copy number alteration are shown in (Table 6); there was no significant association. As with PIK3CA, no difference was observed for the KRAS and BRAF copy number alternation (data not shown).

\section{Kaplan-Meier curves of over-all survival and disease-free} survival by Copy number status

Tumor recurrence and death occurred in 49 patients (42.6\%) and 22 patients (19.1\%), respectively during the median follow-up period of 723 days. Over-all survival and disease-free survival curves were generated using the Kaplan-Meier method, and log-rank tests were used to determine if survival was associated with the copy number status of PIK3CA. There was no significant association between the copy number status (with or without amplification) in PIK3CA and the over-all survival and disease-free survival (Log-rank test, $\mathrm{p}=0.45$ and $\mathrm{p}=0.26$ ) (Figure 1). We conducted same examination in KRAS copy number status, and the significant difference was not found in the copy number status and prognosis.

However, after excluding the patients with lymph node metastasis, the disease-free survival curves drawn using
Table 5 Copy number alteration of K-RAS, PI3CA, BRAF

\begin{tabular}{llll}
\hline & Not Amplified & Amplification & Deletion \\
\hline K-RAS (12p12.1) & $103(89.6 \%)$ & $10(8.7 \%)$ & $2(1.7 \%)$ \\
\hline PIK3CA(3q26.3) & $77(67.0 \%)$ & $37(32.1 \%)$ & $1(0.9 \%)$ \\
\hline BRAF (7q34) & $106(92.2 \%)$ & $2(1.7 \%)$ & $7(6.1 \%)$
\end{tabular}

We identified copy number changes in PIK3CA, K-RAS and BRAF. PIK3CA copy number amplification was found in 37 cases (32.2\%).

the Kaplan-Meier method about 59 patients without lymph node metastasis ( $\mathrm{N}$ stage $=\mathrm{N} 0$ patients) indicated that the patients with PIK3CA copy number amplification $(n=16)$ showed earlier recurrence than those without PIK3CA copy number amplification $(n=43)$ (log-rank test, $p=0.026$ ) (Figure 2). Of those with PIK3CA copy number amplification, $31 \%$ were diseasefree at 2.0 years, whereas $90 \%$ of the patients without PIK3CA copy number amplification survived without recurrence during the study period. Actually 19 patients had a recurrence in PIK3CA amplified patients and 30 patients had a recurrence in not amplified patients. Copy number amplification of the PIK3CA is associated with poor prognosis in HNSCC patients without lymph node metastasis.

\section{Cox proportional hazard models with multivariate adjustment}

Cox proportional hazard models with disease-free survival were computed to determine the significance of PIK3CA amplification with adjustment for age, gender, smoking status and mutation status (Table 7). Without multivariate analysis, PIK3CA amplification showed a significant crude HR. With multivariate analysis, patients with PIK3CA amplification showed poor prognostic markers: adjusted HR, 3.13; 95\% CI, 1.16 to 8.40; $\mathrm{P}=0.024$. In contrast, the factor (age, gender, smoking status and mutation status) showed no significant association with disease-free survival.

\section{Discussion}

The overall mutation frequency of KRAS, BRAF and PIK3CA in our HNSCC samples was lower than reported for other cancers. We identified mutations in $2.6 \%$ of our samples for the KRAS gene, $2.6 \%$ for

Table 4 HNSCC gene mutations

\begin{tabular}{|c|c|c|c|c|c|c|}
\hline No & Nucleotide change & Amino acid Change & Primary tumor & Exon & Smoking (pack/year) & Age/Sex \\
\hline 12 & Substitution of $\mathrm{G}$ for $\mathrm{C}$ at nucleotide 35 & G12A & Oral Cavity (T3NOMO) & KRAS Exon 1 & 45 & $51 / \mathrm{M}$ \\
\hline 21 & Substitution of $\mathrm{G}$ for $\mathrm{C}$ at nucleotide 35 & G12A & Oropharyngeal (T2NOM0) & KRAS Exon1 & 10 & $47 / M$ \\
\hline 30 & Substitution of $\mathrm{G}$ for $\mathrm{C}$ at nucleotide 35 & G12A & Oral Cavity (T3N1M0) & KRAS Exon1 & 0 & $54 / \mathrm{M}$ \\
\hline 10 & Substitution of $\mathrm{A}$ for $\mathrm{G}$ at nucleotide 3140 & H1047R & Laryngeal (T3NOM0) & PIK3CA Exon20 & 0 & $61 / \mathrm{M}$ \\
\hline 51 & Substitution of G for A at nucleotide 1633 & E545K & Oral Cavity (T1N1M0) & PIK3CA Exon9 & 0 & $79 / \mathrm{M}$ \\
\hline 53 & Substitution of G for A at nucleotide 1633 & E545K & Oral Cavity (T3NOMO) & PIK3CA Exon9 & 0 & $82 / \mathrm{M}$ \\
\hline
\end{tabular}

We sequenced KRAS exon 1, BRAF exon 15 and PIK3CA exon 9 and exon 20 and identified mutations in six of the 115 patients (5.2\%). 
Table 6 Patients' characteristics stratified by Copy number alternation of PIC3CA

\begin{tabular}{|c|c|c|c|}
\hline Variable & Copy number of PIK3CA (Not Amplified $n=78$ ) & Copy number of PIK3CA (Amplification $n=37$ ) & $P$ value \\
\hline Age: mean \pm SD & $64.8 \pm 11.6$ & $65.6 \pm 9.9$ & $0.60^{*}$ \\
\hline Sex: Male/Female & $63 / 15$ & $30 / 7$ & $0.96^{\dagger}$ \\
\hline \multicolumn{4}{|l|}{ Number of metastatic } \\
\hline Lymph nodes: & $0 / 0 / 1.5$ & $0 / 0 / 0$ & $0.65^{\ddagger}$ \\
\hline \multicolumn{4}{|l|}{$25 \% / 50 \% / 75 \%$} \\
\hline Primary site & & & $0.39^{\dagger}$ \\
\hline Oropharyngeal & 15(19.2\%) & $10(27.0 \%)$ & \\
\hline Hypopharyngeal & $16(20.5 \%)$ & $9(24.3 \%)$ & \\
\hline Laryngeal & 15(19.2\%) & $8(21.6 \%)$ & \\
\hline Oral cavity & $22(28.2 \%)$ & $9(24.3 \%)$ & \\
\hline Nasal cavity & $10(12.8 \%)$ & $1(2.7 \%)$ & \\
\hline Tumor grade: & $28 / 35 / 15$ & $18 / 12 / 7$ & $0.37^{\dagger}$ \\
\hline well/ moderate/poor & $(35.9 \% / 44.9 \% / 19.2 \%)$ & $(48.6 \% / 32.4 \% / 18.9 \%)$ & \\
\hline \multicolumn{4}{|l|}{ TNM classification } \\
\hline \multirow[t]{2}{*}{ T stage: $\mathrm{T} 1 / \mathrm{T} 2 / \mathrm{T} 3 / \mathrm{T} 4$} & $12 / 30 / 17 / 19$ & $4 / 15 / 10 / 8$ & $0.85^{\dagger}$ \\
\hline & $(15.3 \% / 38.5 \% / 21.8 \% / 24.4 \%)$ & $(10.8 \% / 40.5 \% / 27.0 \% / 21.6 \%)$ & \\
\hline \multirow[t]{2}{*}{ N stage: N0/N1/N2 } & $43 / 12 / 23$ & $16 / 5 / 16$ & $0.34^{+}$ \\
\hline & $(55.1 \% / 15.4 \% / 29.5 \%)$ & $(43.2 \% / 13.5 \% / 43.2 \%)$ & \\
\hline \multirow[t]{2}{*}{ Stage : I/ II/II/IV } & $11 / 16 / 17 / 34$ & $1 / 7 / 9 / 20$ & $0.28^{+}$ \\
\hline & $(14.1 \% / 20.5 \% / 21.8 \% / 43.6 \%)$ & (2.7\%/18.9\%/ 24.3\%/54.1\%) & \\
\hline Pack-year(tobacco) mean \pm SD & $19.6 \pm 24.3$ & $22.3 \pm 24.6$ & $0.64^{*}$ \\
\hline
\end{tabular}

"Student $\mathrm{t}$ test + Chi-square test ₹ Fisher test.

The patients' characteristics stratified by the PIK3CA copy number alteration. There was no significant association.

PIK3CA and $0 \%$ for BRAF. KRAS mutations are observed in approximately $45-60 \%$ of pancreatic cancers $[21,22], 30-50 \%$ of colorectal cancers $[23,24]$ and $30 \%$ of non-small-cell lung carcinomas [25]. BRAF mutations are observed in approximately $60-70 \%$ of malignant melanomas [26,27], 40\% of thyroid carcinomas [28] and 5-10\% of colorectal cancers [29]. PIK3CA mutations are observed in 32\% of colorectal cancers [30], 31\% of endometrial cancers [31] and $14 \%$ of breast cancers [32]. The small sample size may have caused less frequency of these mutations in the study.

The KRAS mutations identified in three of our tumor samples (2.6\%) were identical G12A substitutions, which is a well-characterized activating mutation. The low KRAS mutation frequency in the present study is in agreement with previous small-scale studies of HNSCC that reported a mutation frequency of $2.4 \%$ (1/42 samples) in oral squamous cell carcinoma [10], 4.5\% (1/22 samples) in oropharyngeal cancer [33] and $0 \%(0 / 16$ samples) in HNSCC [9]. We also found that the frequency of copy number amplification was not high (8.7\%), suggesting that approximately $90 \%$ of the patients have normal KRAS proteins and that the hyper activation of KRAS, per se, is not a common feature of HNSCC. A recent study showed that KRAS mutations result in resistance to cetuximab in colorectal cancer, limiting the utility of this drug [34]. In lung cancer, although the frequency of KRAS mutations is similar to that in colorectal cancer, these mutations are not reported to be a predictive marker. Therefore, the low KRAS mutation frequency of HNSCC may cause difficulty in predicting the effect of cetuximab and other EGFR inhibitors.

We analyzed exon 15 of BRAF to search for a V600E substitution, the most common activating mutation of BRAF, which is observed at high frequencies in various cancers [35]. However, we did not detect any V600E mutations in our samples, and the frequency of copy number alteration was also low, at $1.7 \%$ (2/115). Together with a previous study that reported a BRAF mutation frequency of $2.4 \%(1 / 42)$ in oral squamous cell carcinoma [10], our results suggest that the BRAF mutation frequency is much lower in HNSCC than in other cancers.

Mutations in exons 9 and 20 of PIK3CA were found in three specimens (2.6\%), and these mutations are known to be hotspot mutations that generate a constitutively active kinase in other cancers [36]. The mutation frequency of PIK3CA in our study was somewhat lower than that reported in previous small-scale studies. One study of surgical specimens from 30 Americans with HNSCC and eight HNSCC cell lines found mutations in four out of the 38 samples (10.5\%) [37]. Another study 


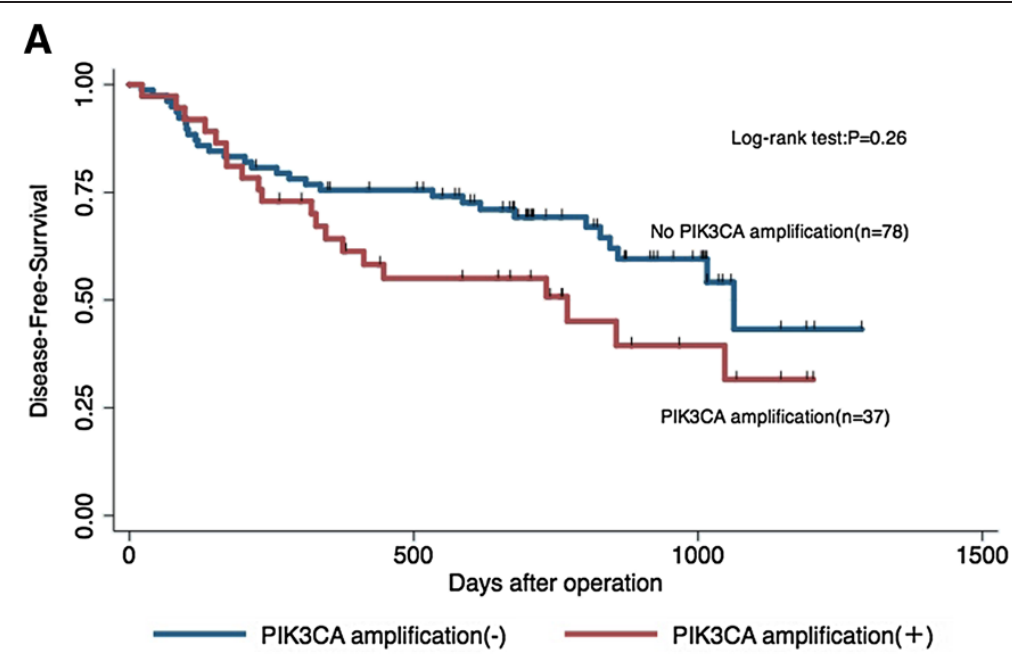

B

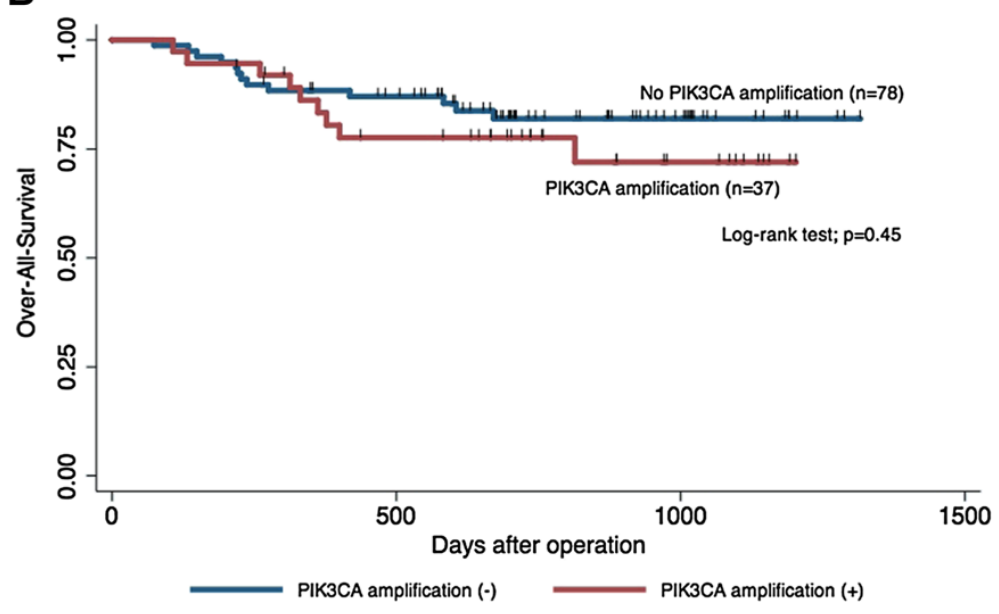

Figure 1115 patients with PIK3CA copy number status. Kaplan-Meier curves for disease-free survival (A) and over-all survival (B). Patients were with or without PIK3CA copy number amplification. The p-values were estimated using the log-rank test.

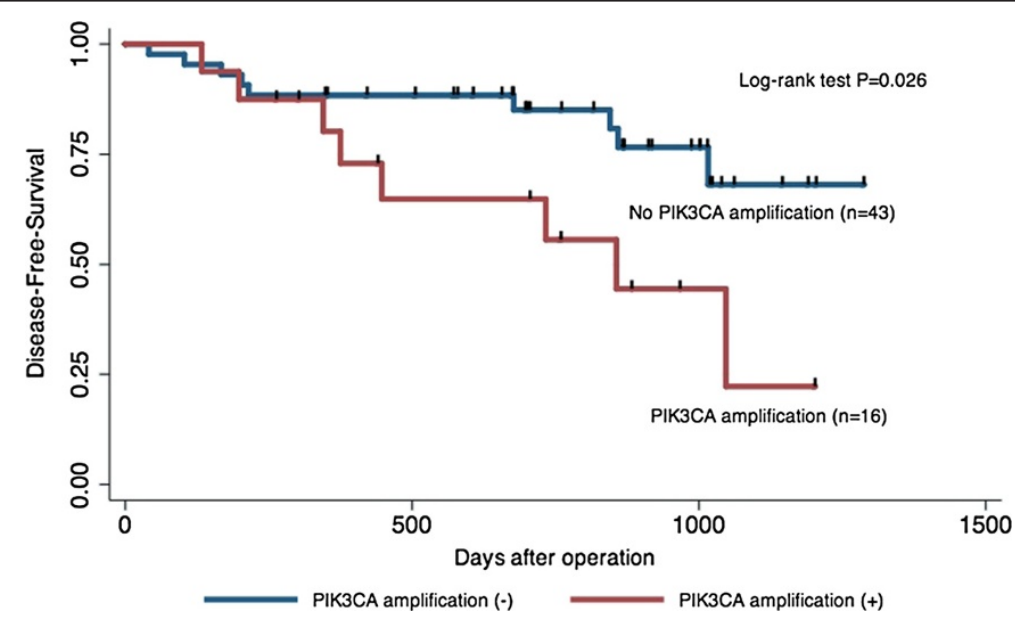

Figure 2 Restricting 59 patients without lymph node metastases. Kaplan-Meier curves for disease-free survival. Patients with or without amplification in PIK3CA, restricting to 59 patients without lymph node metastases. The p-values were estimated using the log-rank test. 
Table 7 Cox proportional hazard models (59 patients without lymph node metastasis)

\begin{tabular}{ccccccc}
\hline Variable & Crude HR & $\mathbf{9 5 \% ~ C l}$ & $\boldsymbol{P}$ value & AHR & $\mathbf{9 5 \% ~ C l}$ & $\boldsymbol{P}$ value \\
\hline PIK3CA amplification & 2.83 & $1.08-7.36$ & 0.003 & 3.13 & $1.16-8.4$ & 0.024 \\
\hline Mutation (PIK3CA K-Ras) & 0.73 & $0.09-5.6$ & 0.77 & 0.83 & $0.1-6.78$ & 0.86 \\
\hline Age & 0.97 & $0.93-1.00$ & 0.13 & 0.95 & 0.075 \\
\hline Gender & 1.22 & $0.52-2.84$ & 0.64 & 1.06 & $0.42-2.65$ & 0.89 \\
\hline Smoking status & 1.01 & $0.99-1.03$ & 0.08 & 1.02 & $0.99-1.04$ \\
\hline
\end{tabular}

Adjusted for age, gender, smoking status, mutation status.

$\mathrm{HR}$, hazard ratio; $\mathrm{Cl}$, confidence interval; $\mathrm{AHR}$, adjusted hazard ratio.

Cox proportional hazard models were computed to determine the significance of PIK3CA amplification with adjustment for age, gender, smoking status and mutation status.

found mutations in two surgical specimens and five cell lines among 54 cases, including 17 cell lines and 18 surgical specimens from Vietnamese patients and 19 surgical specimens from Indian patients [38]. The lower mutation frequency may reflect differences in the genetic backgrounds or may be due to the small population sizes. Although the frequency of point mutations in PIK3CA was low, we found copy number amplification in 37 samples (32.2\%), suggesting that the hyper activation of the PI3K pathway occurs in one-third of HNSCC patients. PIK3CA mutations are associated with resistance to cetuximab in colorectal cancer in vitro [8]. Furthermore, a phase I study of a recently developed mTOR inhibitor found that colorectal cancer patients with PIK3CA mutations had a higher response rate than those without mutations [39]. Thus, checking the status of the PIK3CA gene will be important when using these molecularly targeted drugs in HNSCC patients. However, the low frequency of mutation in PIK3CA complicates its utility as a predictive marker for use in molecularly targeted medicine in clinical settings.

In our analysis, an amplification of the PIK3CA copy number was found in many of the samples (32.2\%). With regard to lung cancer, such amplification is more frequent in squamous cell carcinomas (33.1\%) than adenocarcinomas (6.2\%) [40]. Interestingly, Fendri et al. reported that the frequency of amplification was $21.6 \%$ and was associated with lymph node metastasis and with the overall survival in nasopharyngeal cancer [41]. In HNSCC, metastatic lymph nodes are very strongly associated with disease progression and clinical staging: the cancer is considered stage III or IV when lymph node metastases are found. Therefore, we hypothesized that the copy number amplification of PIK3CA was associated with a poor prognosis. The frequency of the copy number alteration observed in the present study was the same as in other reports, yet we found no significant difference in the disease-free survival and overall survival between patients with PIK3CA amplification and those without amplification. However, when the patients with lymph node metastases were excluded from the population, a significant correlation was found between
PIK3CA copy amplification and the time to relapse (logrank test, $p=0.026$ ). As cancer relapse occurs in the lymph nodes in most cases, the amplification of the PIK3CA copy number is likely to promote the process of lymph node metastasis in early-stage patients. Our evidence further suggests that those patients with earlystage HNSCC may be divided into two subgroups of good and poor prognoses, as defined by the copy number status of PIK3CA.

The limitations of this study include the small number of patients especially about the prognosis study by the status of the copy number and may be include the selection bias in undergoing surgery.

\section{Conclusions}

We examined the mutations and copy number alterations of KRAS, BRAF and PIK3CA in 115 clinical specimens of HNSCC. We identified 3 mutations (2.6\%) in K-RAS and 3 mutations (2.6\%) in PIK3CA. Copy number amplification was found in 37 cases (32.1\%) for PIK3CA, 10 cases (8.7\%) for K-RAS and 2 cases (1.7\%) for BRAF. Kaplan-Meier survival analysis revealed that copy-number amplification of PIK3CA was markedly associated with cancer relapse in patients without lymph node metastasis. (Log-rank test, $\mathrm{p}=0.026$ ) Copy number amplification of the PIK3CA gene is associated with poor prognosis in HNSCC patients without lymph node metastasis.

\section{Competing interests}

No potential conflicts of interest were disclosed.

\section{Authors' contributions}

Conception/Design: TH, TS, MU Financial support: TH, YY, MU Administrative support: TH, TS, SK, YY, MU Provision of study materials: TH, TS, TK, HM Collection/assembly of data: TH, TS, MY, TK, HM, Data analysis: TH, TS, MU Manuscript writing: TH, TS, SK. All authors read and approved the final manuscript.

\section{Acknowledgment}

This research was partially supported by High Technology Research Center Project for Private University and the Ministry of Education, Science, Sports and Culture, Grant-in-Aid for Young Scientists (B). 


\section{Author details}

${ }^{1}$ Department of Oto-Rhino-Laryngology, Jikei University School of Medicine, 3-25-8 Nishi-shimbashi, Minato-ku, Tokyo 105-8461, Japan. Division of Molecular Epidemiology, Jikei University School of Medicine, Minato-ku, Tokyo, Japan. ${ }^{3}$ Division of Invertebrate Genetics, National Institute of Genetics, Mishima, Japan. ${ }^{4}$ Department of Pediatrics, Jikei University School of Medicine, Minato-ku, Tokyo, Japan.

Received: 27 January 2012 Accepted: 3 September 2012 Published: 20 September 2012

\section{References}

1. Lockwood WW, Coe BP, Williams AC, MacAulay C, Lam WL: Whole genome tiling path array CGH analysis of segmental copy number alterations in cervical cancer cell lines. Int J Cancer 2007, 120:436-443.

2. Muller S, Su L, Tighiouart M, Saba N, Zhang H, Shin DM, Chen ZG: Distinctive E-cadherin and epidermal growth factor receptor expression in metastatic and nonmetastatic head and neck squamous cell carcinoma predictive and prognostic correlation. Cancer 2008, 113:97-107.

3. Hama T, Yuza Y, Saito Y, O-uchi J, Kondo S, Okabe M, Yamada H, Kato T, Moriyama H, Kurihara S, Urashima M: Prognostic significance of epidermal growth factor receptor phosphorylation and mutation in head and neck squamous cell carcinoma. The Oncologist 2009, 14:900-908.

4. Burtness B, Goldwasser MA, Flood W, Mattar B, Forastiere AA: Phase III randomized trial of cisplatin plus placebo compared with cisplatin plus cetuximab in metastatic/recurrent head and neck cancer: an Eastern Cooperative Oncology Group study. J Clin Oncol 2005, 23:8646-8654.

5. Sharma SV, Bell DW, Settleman J, Haber DA: Epidermal growth factor receptor mutations in lung cancer. Nat Rev Cancer 2007, 7:169-81.

6. Berg M, Danielsen SA, Ahlquist T, Merok MA, Ågesen TH, Vatn MH, Mala T, Sjo OH, Bakka A, Moberg I, Fetveit T, Mathisen Ø, Husby A, Sandvik O, Nesbakken A, Thiis-Evensen E, Lothe RA: DNA sequence profiles of the colorectal cancer critical gene set KRAS-BRAF-PIK3CA-PTEN-TP53 related to age at disease onset. PLoS One 2010, 5:e13978.

7. Karapetis CS, Khambata-Ford S, Jonker DJ, O'Callaghan CJ, Tu D, Tebbutt NC, Simes RJ, Chalchal H, Shapiro JD, Robitaille S, Price TJ, Shepherd L, Au HJ, Langer C, Moore MJ, Zalcberg JR: K-ras mutations and benefit from cetuximab in advanced colorectal cancer. N Engl J Med 2008, 359:1757-1765.

8. Jhawer M, Goel S, Wilson AJ, Montagna C, Ling YH, Byun DS, Nasser S, Arango D, Shin J, Klampfer L, Augenlicht LH, Perez-Soler R, Mariadason JM: PIK3CA mutation/PTEN expression status predicts response of colon cancer cells to the epidermal growth factor receptor inhibitor cetuximab. Cancer Res 2008, 68:1953-1961.

9. Kondo N, Tsukuda M, Taguchi T, Nakazaki K, Sakakibara A, Takahashi H, Toth G, Nishimura G: Gene status of head and neck squamous cell carcinoma cell lines and cetuximab-mediated biological activities. Cancer Sci 2011, 102:1717-23.

10. Bruckman KC, Schönleben F, Qiu W, Woo VL, Su GH: Mutational analyses of the BRAF, KRAS, and PIK3CA genes in oral squamous cell carcinoma. Oral surg Oral Med 2010, 110:632-637.

11. Hirsch FR, Varella-Garcia M, Bunn PA Jr, Di Maria MV, Veve R, Bremmes RM, Barón $A E$, Zeng C, Franklin WA: Epidermal growth factor receptor in nonsmall-cell lung carcinomas: correlation between gene copy number and protein expression and impact on prognosis. J Clin Oncol 2003, 21:3798-3807.

12. Chung $C H$, Ely $K$, McGavran L, Varella-Garcia M, Parker J, Parker N, Jarrett C, Carter J, Murphy BA, Netterville J, Burkey BB, Sinard R, Cmelak A, Levy S, Yarbrough WG, Slebos RJ, Hirsch FR: Increased epidermal growth factor receptor gene copy number is associated with poor prognosis in head and neck squamous cell carcinomas. J Clin Oncol 2006, 24:4170-4176.

13. Fenic I, Steger K, Gruber C, Arens C, Woenckhaus J: Analysis of PIK3CA and Akt/protein kinase B in head and neck squamous cell carcinoma. Oncol Rep 2007, 18:253-259.

14. O'Sullivan B, Shah J: New TNM staging criteria for head and neck tumors. Semin Surg Oncol 2003, 21:30-42.

15. Soh J, Okumura N, Lockwood WW, Yamamoto $H$, Shigematsu $H$, Zhang W, Chari R, Shames DS, Tang X, MacAulay C, Varella-Garcia M, Vooder T, Wistuba II, Lam S, Brekken R, Toyooka S, Minna JD, Lam WL, Gazdar AF: Oncogene mutations, copy number gains and mutant allele specific imbalance (MASI) frequently occur together in tumor cells. PLoS One 2009, 4:e7464.

16. Livak KJ, Schmittgen TD: Analysis of relative gene expression data using real-time quantitative PCR and the 2(-Delta Delta $C(T)$ ) Method. Methods 2001, 25:402-408.

17. Kolasa IK, Alina R, Anna F, Izabela Z-S, Magdalena M, Joanna M, Agnieszka T, Agnieszka Dansonka M, Jolanta K: PIK3CA amplification associates with resistance to chemotherapy in ovarian cancer patients. Cancer Biology \& Therapy 2009, 8:1-6.

18. Gandhi J, Zhang J, Xie Y, Soh J, Shigematsu H, Zhang W, Yamamoto H, Peyton M, Girard L, Lockwood WW, Lam WL, Varella-Garcia M, Minna JD, Gazdar AF: Alterations in genes of the EGFR signaling pathway and their relationship to EGFR tyrosine kinase inhibitor sensitivity in lung cancer cell lines. PLoS One 2009, 4:e4576.

19. Przybytkowski E, Ferrario C, Basik M: The use of ultra-dense array CGH analysis for the discovery of micro-copy number alterations and gene fusions in the cancer genome. BMC Med Genomics 2011, 4:16.

20. Ahrens W, Jöckel KH, Patzak W, Elsner G: Alcohol, smoking, and occupational factors in cancer of the larynx: a case-control study. Am Ind Med 1991, 20:477-93.

21. Schönleben F, Qiu W, Bruckman KC, Ciau NT, Li X, Lauerman MH, Frucht $H$ Chabot JA, Allendorf JD, Remotti HE, Su GH: BRAF and KRAS gene mutations in intraductal papillary mucinous neoplasm /carcinoma (IPMN/IPMC) of the pancreas. Cancer Lett 2007, 249:242-248.

22. Bournet B, Souque A, Senesse $P$, Assenat E, Barthet M, Lesavre N, Aubert A, O'Toole D, Hammel P, Levy P, Ruszniewski P, Bouisson M, Escourrou J, Cordelier P, Buscail L: Endoscopic ultrasound-guided fine-needle aspiration biopsy coupled with KRAS mutation assay to distinguish pancreatic cancer from pseudotumoral chronic pancreatitis. Endoscopy 2009, 41:552-557.

23. Vaughn CP, Zobell SD, Furtado LV, Baker CL, Samowitz WS: Frequency of KRAS, BRAF, and NRAS mutations in colorectal cancer. Genes Chromosomes Cancer 2011, 50:307-312.

24. Liu X, Jakubowski M, Hunt JL: KRAS gene mutation in colorectal cancer is correlated with increased proliferation and spontaneous apoptosis. Am J Clin Pathol 2011, 135:245-252.

25. Cortot AB, Italiano A, Burel-Vandenbos F, Martel-Planche G, Hainaut P: KRAS mutation status in primary nonsmall cell lung cancer and matched metastases. Cancer 2010, 116:2682-2687.

26. Dong J, Phelps RG, Qiao R, Yao S, Benard O, Ronai Z, Aaronson SA: BRAF oncogenic mutations correlate with progression rather than initiation of human melanoma. Cancer Res 2003, 63:3883-3885.

27. Kumar R, Angelini S, Czene K, Sauroja I, Hahka-Kemppinen M, Pyrhönen S, Hemminki K: BRAF mutations in metastatic melanoma: a possible association with clinical outcome. Clin Cancer Res 2003, 9:3362-3368.

28. Kimura ET, Nikiforova MN, Zhu Z, Knauf JA, Nikiforov YE, Fagin JA: High prevalence of BRAF mutations in thyroid cancer: genetic evidence for constitutive activation of the RET/PTC-RAS-BRAF signaling pathway in papillary thyroid carcinoma. Cancer Res 2003, 63:1454-1457.

29. Yuen ST, Davies H, Chan TL, Ho JW, Bignell GR, Cox C, Stephens P, Edkins S, Tsui WW, Chan AS, Futreal PA, Stratton MR, Wooster R, Leung SY: Similarity of the phenotypic patterns associated with BRAF and KRAS mutations in colorectal neoplasia. Cancer Res 2002, 62:6451-6455.

30. Samuels Y, Wang Z, Bardelli A, Silliman N, Ptak J, Szabo S, Yan H, Gazdar A Powell SM, Riggins GJ, Willson JK, Markowitz S, Kinzler KW, Vogelstein B, Velculescu VE: High frequency of mutations of the PIK3CA gene in human cancers. Science 2004, 304:554.

31. Kang S, Seo SS, Chang HJ, Yoo CW, Park SY, Dong SM: Mutual exclusiveness between PIK3CA and KRAS mutations in endometrial carcinoma. Int J Gynecol Cancer 2008, 18:1339-1343.

32. Levine DA, Bogomolniy F, Yee CJ, Lash A, Barakat RR, Borgen PI, Boyd J: Frequent mutation of the PIK3CA gene in ovarian and breast cancers. Clin Cancer Res 2005, 11:2875-2878.

33. Van Damme N, Deron P, Van Roy N, Demetter P, Bols A, Van Dorpe J, Baert F, Van Laethem JL, Speleman F, Pauwels P, Peeters M: Epidermal growth factor receptor and K-RAS status in two cohorts of squamous cell carcinomas. BMC Cancer 2010, 10:189.

34. Lièvre A, Bachet JB, Boige V, Cayre A, Le Corre D, Buc E, Ychou M, Bouché $O$, Landi B, Louvet C, André T, Bibeau F, Diebold MD, Rougier P, Ducreux M, Tomasic G, Emile JF, Penault-Llorca F, Laurent-Puig P: KRAS mutations as 
an independent prognostic factor in patients with advanced colorectal cancer treated with cetuximab. I Clin Oncol 2008, 26:374-379.

35. Lee JH, Lee ES, Kim YS: Clinicopathologic significance of BRAF V600E mutation in papillary carcinomas of the thyroid: a meta-analysis. Cancer 2007, 110:38-46

36. Kataoka Y, Mukohara T, Shimada H, Saijo N, Hirai M, Minami H: Association between gain-of-function mutations in PIK3CA and resistance to HER2-targeted agents in HER2-amplified breast cancer cell lines. Ann Oncol 2010, 21:255-262.

37. Qiu W, Schönleben F, Li X, Ho DJ, Close LG, Manolidis S, Bennett BP, Su GH: PIK3CA mutations in head and neck squamous cell carcinoma. Clin Cancer Res 2006, 12:1441-1446.

38. Murugan AK, Hong NT, Fukui Y, Munirajan AK, Tsuchida N: Oncogenic mutations of the PIK3CA gene in head and neck squamous cell carcinomas. Int J Oncol 2008, 32:101-111.

39. Janku F, Tsimberidou AM, Garrido-Laguna I, Wang X, Luthra R, Hong DS, Naing A, Falchook GS, Moroney JW, Piha-Paul SA, Wheler JJ, Moulder SL, Fu S, Kurzrock R: PIK3CA mutations in patients with advanced cancers treated with PI3K/AKT/mTOR axis inhibitors. Mol Cancer Ther 2011, 10:558-565

40. Yamamoto H, Shigematsu H, Nomura M, Lockwood WW, Sato M, Okumura N, Soh J, Suzuki M, Wistuba II, Fong KM, Lee H, Toyooka S, Date H, Lam WL, Minna JD, Gazdar AF: PIK3CA mutations and copy number gains in human lung cancers. Cancer Res 2008, 68:6913-6921.

41. Fendri A, Khabir A, Mnejja W, Sellami-Boudawara T, Daoud J, Frikha M, Ghorbel A, Gargouri A, Mokdad-Gargouri R: PIK3CA amplification is predictive of poor prognosis in Tunisian patients with nasopharyngeal carcinoma. Cancer Sci 2009, 100:2034-2039.

doi:10.1186/1471-2407-12-416

Cite this article as: Suda et al:: Copy Number Amplification of the PIK3CA Gene Is Associated with Poor Prognosis in Non-lymph node metastatic Head and Neck Squamous Cell Carcinoma. BMC Cancer 2012 $12: 416$

\section{Submit your next manuscript to BioMed Central and take full advantage of:}

- Convenient online submission

- Thorough peer review

- No space constraints or color figure charges

- Immediate publication on acceptance

- Inclusion in PubMed, CAS, Scopus and Google Scholar

- Research which is freely available for redistribution 